\title{
The influence of ethics education on awareness of nursing students with no clinical experience regarding the code of ethics: A case study
}

\author{
Se-Won Kang * \\ Department of Nursing, Dongseo University, Busan, South Korea
}

Received: February 16, 2017

DOI: $10.5430 /$ jnep.v7n10p12

\author{
Accepted: April 16, 2017 \\ Online Published: April 20, 2017 \\ URL: https://doi.org/10.5430/jnep.v7n10p12
}

\begin{abstract}
The purpose of this study was to evaluate the influence of ethics education on Korean nursing students' awareness regarding the code of ethics. This study employed a one group pretest-posttest design. The participants were 48 sophomore nursing students with no clinical experience from a city in Korea. In this study, ethics education involved lectures related to "nursing ethics and professionalism". Data were collected in September and December 2016. The collected data were analyzed using means, standard deviations, and paired $t$ tests. The mean score on awareness regarding the code of ethics increased from 3.75 to 4.40 after the ethics education $(t=6.350, p<.001)$. Scores on the sub-domains of nurses and patients, obligations of nurses as experts, and nurses and cooperators also increased significantly $(t=6.224, t=5.436, t=4.969$, respectively, all $p<.001)$. In this study, ethics education was found to raise nursing students' awareness regarding the code of ethics. Both awareness and practice of the code of ethics are crucial for adherence to the moral standards of professional behaviors required from medical professionals. Ethics education needs to be implemented, as it is indispensable for building a desirable ethical value system among future medical professionals and for enabling them to put ethical behaviors into practice by improving their moral judgment and sensitivity.
\end{abstract}

Key Words: Ethics education, Code of ethics, Nursing, Students

\section{INTRODUCTION}

Specialized ethics education is very important for professionals, and it is a global issue. Professional ethics in nursing is a basis of the nursing profession. Nurses' professional ethics consist of their values, rights, duties, and responsibilities, and this ethics code is used to interact with patients, clients, colleagues, and other professionals. The overall objective of professional ethics is to guide nurses to contribute to the development of a healthy society. ${ }^{[1]}$

The rapid advancement in biotechnology and medical technology has brought medical achievements to human beings in the form of health promotion and life extension, but it has also significantly increased concerns that the dignity of human life could be encroached upon. ${ }^{[2]}$ In addition, nurses who take care of clients in clinical settings, unlike in the past, are often confronted with various ethical issues, such as research ethics related to clinical trials, including stem cells and gene therapy; issues related to birth, such as embryo reproduction, abortion, and surrogate motherhood; and questions related to life-sustaining treatments, the process of death, and so forth. ${ }^{[3]}$

In order to help establish a value system in students, nursing

\footnotetext{
*Correspondence: Se-Won Kang; Email: swkang75@ @otmail.com; Address: Department of Nursing, Dongseo University, 47 Jurye-ro, Sasang-gu, Busan 47011, South Korea.
} 
education needs to employ a holistic approach. This would not only help to expand students' intellectual capacity but it would also cultivate emotionally stable and morally mature human beings. Furthermore, it would raise ethical awareness, which is necessary for resolving the various ethical issues that nurses may encounter in the clinical setting. ${ }^{[4,5]}$ The ethical education makes nursing students ready to handle the ethical conflicts that they may encounter during their clinical practice. ${ }^{[6]}$ Therefore, it is necessary for nursing education to focus on developing an understanding of desirable nursing behaviors, which will improve students' ability to cope with different medical ethical problems that they might encounter when working as nurses in the future. ${ }^{[7,8]}$

Professional ethics are highly emphasized for medical professionals dealing with human life. ${ }^{[9]}$ Furthermore, professional organizations enforce their codes of ethics, albeit not laws, to maintain morality in professional behavior, especially in relation to the responsibilities of the profession. ${ }^{[10]}$ The Korean Nurses Association, published the nation's first Code of Nursing Ethics in 1972, and it has been revised 4 times to date: 1983, 1995, 2006, and 2013. The revisions were intended to alter the code with reference to the rapidly changing medical environment and to specify the socially expected virtues, in order to help raise ethical awareness among both nurses and nursing students. ${ }^{[11]}$ The Code of Nursing Ethics covers topics related to nurses and nursing clients, obligations of nurses as professionals, dignity of human life, and respect for the basic rights of nurses and cooperators.

In nursing education in Korea, owing to the growing awareness regarding bioethics, nursing ethics courses have been offered as a part of the curriculum. Such nursing ethics courses are offered as mandatory courses since "legal and ethical responsibility for the development of the nursing profession" is recognized as a core competence of nurses according to the Korean Accreditation Board of Nursing Education (2012). ${ }^{[12]}$ Therefore, nursing ethics education is commonly provided for undergraduate nursing students in most nursing colleges; however, consensus on the content and teaching modules for these ethics courses has still not been established. ${ }^{[13]}$

It has been suggested that education on the code of ethics might help to establish the identity of professional nursing behaviors and promote professional development. ${ }^{[4]}$ In addition, it has been argued that educational interventions or experiential stimulation should be implemented since the initial stage of theoretical education and clinical practice, to help students to recognize the code of nursing ethics and promote the establishment of professional values. ${ }^{[14,15]}$

Thus, it has been suggested that nursing students could learn to develop desirable relationships with other nurses, nursing clients as humans, and various cooperators as a result of ethics education, as well as to understand their professional obligations as experts and to establish desirable professional values. Although there have been some preceding studies $^{[13,16,17]}$ measuring the influence of ethics education, few have measured the influence of ethics education based on the extent of change in awareness regarding the code of ethics. Changes in nursing students' awareness regarding the ethics code can increase application in practice. Thus, this study aimed to evaluate the influence of ethics education on nursing students' awareness regarding the code of ethics.

\section{Methods}

\subsection{Study design}

This study employed a one group pretest-posttest design to evaluate the effect of ethics education on nursing students' awareness regarding the code of ethics.

\subsection{Ethical considerations regarding participants and data collection procedures}

This study was conducted in accordance with the guidelines of the university committee on research on human subjects. Written consent was obtained after explaining the purpose of the study to subjects who expressed the intention to participate voluntarily. Questionnaires were distributed to nursing students who agreed to participate in the survey, and were collected after completion. It took about 3-5 minutes to complete the questionnaires. Among the 57 questionnaires collected, 48 were used for the data analyses as they contained complete information at both pretest and posttest.

The participants in this study were sophomore nursing students from a university located in a city in South Korea. Sophomores who belong to the department of nursing science at universities in Korea do not have any clinical practice experience as the clinical practice course of about 1,000 hours commences in the junior year, lasting for 2 years thereafter.

\subsection{Structure of nursing ethics education}

The nursing ethics education was provided 13 times, from September to December 2016, and it comprised 90-min sessions each week. In this study, ethics education involved lectures related to "nursing ethics and professionalism" (see Table 1).

The content of these lectures were based on the learning objectives of nursing ethics and professionalism recommended by the Korean Academy of Nursing Administration (2012). ${ }^{[18]}$ These learning objectives include the concept of nursing ethics, bioethics, ethical thinking, nurses' code 
of ethics, ethics pertaining to nurses and clients, ethics pertaining to nurses and cooperators, ethics of nursing practice, characteristics of the nursing profession, and professional establishment.

The lectures covered ethics (including ethics, nursing ethics, and theories and principles of ethics) for 2 weeks; bioethics for 2 weeks; code of nursing ethics, declaration of ethics, and ethical guidelines for 1 week; nurses and ethics-related conflicts for 2 weeks; understanding of the nursing profession for 2 weeks; activity area of nurses' responsibilities for 2 weeks; and conflicts in and development of the nursing profession for 2 weeks.

Table 1. Details of the ethics education

\begin{tabular}{llc}
\hline Week & Ethical education topics & Education method \\
\hline 1 & Ethics and nursing ethics & ・ Lecture by professor (50 minutes) \\
2 & Ethical theories and principles & - Basic lecture on topic \\
3 & Bioethics & - Related materials, videos, movies, \\
4 & Bioethics & documentaries, press releases, judicial \\
5 & Code of nursing ethics and declaration of ethics, ethical guidelines & precedents, etc. \\
6 & Nurses and ethical controversies & Student group presentation (40 minutes) \\
7 & Nurses and ethical controversies & - Selection of ethical issues related to \\
8 & Understanding of nursing profession & nurses \\
9 & Understanding of nursing profession & Theoretical basis \\
10 & Activity area of nurses & Discussion on pros and cons \\
11 & Activity area of nurses & - Sudiovisual materials, role play, etc. \\
12 & Controversies and development of nursing profession & \\
13 & Controversies and development of nursing profession &
\end{tabular}

The sessions consisted mainly of lectures on basic theories introduced by professors, followed by presentation of related material such as videos, films, press releases, etc., and group presentations and discussions by students. Students' group presentations and discussions were conducted as freestyle presentations on a selection of themes regarding ethical conflicts related to nurses. Students expressed theory-based perspectives on pros and cons in ethical conflicts. Many of the topics selected by students were related to bioethics and involved ethical issues related to birth, death, treatment and nursing, research, and nursing care and organizational culture. Specifically, issues were chosen freely, including ethical issues that could be faced by nurses, such as biomedical ethics; issues related to abortion, surrogacy, brain death, transplantation, euthanasia, and rejection of transfusion; ethics pertaining to terminally ill patients; ethics in the relationship between doctors and hospital employees; relational ethics; etc. Several discussions were conducted regarding these issues.

\subsection{Measurement}

\section{Questionnaire on awareness regarding the code of ethics}

The questionnaire on awareness regarding the code of ethics comprised 15 items that correspond to the 4th Korean Code of Nursing Ethics ${ }^{[11]}$ (Korean Nurses Association, 2013).
The content of each question has been presented in Table 2 . The questionnaire assessed the participants' recognition of the contents of each item on a scale of 1 to 5 ( $5=$ Always Aware, 4 = Fairly Aware, 3 = Usually Aware, 2 = Slightly Aware, $1=$ Not Aware). Higher scores indicated higher awareness regarding the code of ethics. In a preceding study (Kim et al. 2013) ${ }^{[19]}$ that measured awareness based on the 3rd Code of Ethics, the Cronbach's alpha of the assessment tool was 0.927. In this study, the Cronbach's alpha for the questionnaire was 0.922 (see Table 1).

The 15 items consisted of 6 questions related to nurses and clients, 6 questions related to obligations of nurses as experts, and 3 questions related to nurses and cooperators. The questions about nurses and clients were associated with equality in nursing care, respect for the individual needs of clients, privacy protection, maintenance of confidentiality, right to know, respect for self-decision making, protection of vulnerable nursing clients, and creation of a healthy environment. The questions about obligations of nurses as experts were related to adherence to nursing standards, education and research, professional activities, promotion of justice and trust, provision of safe nursing, and maintenance of health and decency. The questions about nurses and cooperators were related to compliance with relational ethics, nursing 
client protection, biotechnology, and dignity protection (Korea Nurse Association, 2013). ${ }^{[11]}$

\subsection{Data analyses}

The collected data were analyzed using the PASW Statistics 18.0 program. The change in the extent of awareness regarding the code of ethics after ethics education was analyzed using means, standard deviations, and paired $t$ tests. Statistical significance was set at .05 .

\section{RESULTS}

\subsection{Scores on awareness regarding the code of ethics be- fore ethics education}

The mean awareness score was 3.75 (out of 5) before the ethics education. The mean awareness scores on the subdomains of the code of ethics, nurses and clients, obligations of nurses as experts, and nurses and cooperators, were 3.75, 3.56 , and 3.72 , respectively.

The highest awareness scores were on respecting patients privacy and confidentiality (4.33) and provision of nursing care without discrimination (4.10). The lowest awareness scores were on professional activities (3.35) and education and research (3.44).

\subsection{Scores on awareness regarding the code of ethics af- ter ethics education}

The mean awareness score was 4.40 (out of 5) after the ethics education. The mean awareness scores on the sub-domains of the code of ethics were 4.40, 4.33, and 4.34, on nurses and clients, obligations of nurses as experts, and nurses and cooperators, respectively.

The highest awareness scores were on respecting patients' privacy and confidentiality (4.70) and protection of patients (4.62). The lowest awareness scores were on education and research (4.13), and protection of life, science, and technology, and dignity of patients (4.17).

\subsection{Change in the scores on awareness regarding the code of ethics after ethics education}

The mean scores on awareness regarding the code of ethics increased significantly from 3.75 to 4.40 after the ethics education $(t=6.350, p<.001)$ (see Table 2). Further, a significant increase in awareness scores was also observed on all the three sub-domains of the code of ethics $(t=6.224$, $t=5.436$, and $t=4.969$, on nurses and clients, obligations of nurses as experts, and nurses and cooperators, respectively, all $p<.001)$.

\section{Discussion}

This study aimed to evaluate the influence of ethics education on nursing students' awareness regarding the code of Published by Sciedu Press ethics. Items of the code of nursing ethics included not only bioethics but also various aspects of nurses' relationships with clients, their roles as experts, and their relationship with cooperators.

In this study, the provision of ethics education for university students majoring in nursing science was found to be effective in improving their awareness regarding the code of ethics. Related knowledge increased during the course of the lectures, which were conducted using related audiovisual materials, and the group presentations and discussions on nursing ethics-related issues, which the students may not have considered previously. This knowledge increase might be attributable to the fact that students became familiarized with the code of nursing ethics and learned about the ethical code of conduct of professional nurses.

As nursing ethics education was provided, some of the students expressed that the use of various teaching approaches, including the use of movies, documentary videos, press releases, judicial precedents, discussions, and so on, helped improve their ethics awareness by shifting away from lecturecentric modes. The results of this study were in line with those of studies ${ }^{[20,21]}$ suggesting that creative approaches to nursing ethics education are well received by students. In the future, ethics educators need to consider using various teaching methods to sustain students' interest in topics related to ethics.

The highest improvement in the awareness scores was observed in the areas of protection of vulnerable patients, professional activity, and promotion of justice and trust. This suggests that the ethics education helped improve the nursing students' awareness regarding their social role as medical professionals. These students were sophomores majoring in nursing science, who had not yet been involved in clinical practice, and were expected to gain practical experience regarding the code of ethics only during their clinical practice that would commence in the 1st semester of their junior year. Ethics education is considered to require continuous instruction, and it needs to be tailored to the students' level of ethical awareness based on their grade, to ensure that they can maintain and improve their awareness regarding the code of ethics. The present findings suggest that it would be necessary to use the code of ethics to effectively apply nursing ethics education to nursing practice, as suggested by Vanlaere and Gastmans (2007). ${ }^{[22]}$ Awareness regarding the code of ethics will be maintained if the ethics education is provided continuously to nursing students even during their clinical practice, later during their nursing education. These efforts will help promote the moral judgment of healthcare professionals by increasing their ability to apply ethical knowledge to their practice. 
Table 2. Scores on awareness regarding the code of ethics before and after ethics education

\begin{tabular}{|c|c|c|c|c|}
\hline \multirow[t]{2}{*}{ Variables } & \multirow{2}{*}{$\begin{array}{l}\text { Before } \\
\text { Mean (SD) }\end{array}$} & \multirow{2}{*}{$\begin{array}{l}\text { After } \\
\text { Mean (SD) }\end{array}$} & \multirow{2}{*}{$\begin{array}{l}\text { After-Before } \\
\text { differences } \\
\text { Mean (SD) }\end{array}$} & \multirow[t]{2}{*}{$t(p)$} \\
\hline & & & & \\
\hline Total mean scores of awareness regarding code of ethics & $3.75(0.64)$ & $4.40(0.39)$ & $0.68(0.74)$ & $6.350(<.001)$ \\
\hline Nurse and nursing clients & $3.89(0.59)$ & $4.49(0.47)$ & $0.60(0.67)$ & $6.224(<.001)$ \\
\hline $\begin{array}{l}\text { Provision of nursing care without discrimination: Nurses should provide } \\
\text { care without discrimination, regardless of nationality, race, religion, } \\
\text { ideology, age, sex, political, social, or economic status, sexual } \\
\text { orientation, type and degree of disease and disability, and cultural } \\
\text { differences of nursing clients. }\end{array}$ & $4.10(0.78)$ & $4.54(0.58)$ & $0.44(0.99)$ & $3.070(.004)$ \\
\hline $\begin{array}{l}\text { Respect for individual needs: Nurses should provide care with respect } \\
\text { for personal needs based on customs, beliefs, and values of nursing } \\
\text { clients. }\end{array}$ & $3.75(0.78)$ & $4.46(0.65)$ & $0.71(0.92)$ & $5.325(<.001)$ \\
\hline $\begin{array}{l}\text { Respect for patients' privacy and confidentiality: Nurses should protect } \\
\text { the privacy of nursing clients, maintain confidentiality, and only share } \\
\text { information necessary for nursing. }\end{array}$ & $4.33(0.69)$ & $4.70(0.54)$ & $0.38(0.86)$ & $3.000(.004)$ \\
\hline $\begin{array}{l}\text { Respect for patients' right to know and self-decision making: Nurses } \\
\text { should involve nursing clients in the whole process of nursing and } \\
\text { provide sufficient information and explanations to help nursing clients } \\
\text { make their own decisions. }\end{array}$ & $4.08(0.77)$ & $4.62(0.49)$ & $0.54(0.92)$ & $4.072(<.001)$ \\
\hline $\begin{array}{l}\text { Protection of vulnerable patients: Nurses should provide protection and } \\
\text { care to nursing clients facing vulnerable environments. }\end{array}$ & $3.60(0.92)$ & $4.42(0.65)$ & $0.81(0.98)$ & $5.733(<.001)$ \\
\hline $\begin{array}{l}\text { Creation of a healthy environment: Nurses should participate in the } \\
\text { protection of nursing clients from harmful social environments, } \\
\text { disasters, and ecological contamination that threaten health, and in the } \\
\text { preservation and maintenance of a healthy environment. }\end{array}$ & $3.46(0.94)$ & $4.21(0.65)$ & $0.75(1.14)$ & $4.561(<.001)$ \\
\hline Obligations of nurse as experts & $3.56(0.80)$ & $4.33(0.42)$ & $0.77(0.98)$ & $5.436(<.001)$ \\
\hline $\begin{array}{l}\text { Nursing standards compliance: Nurses should always work in } \\
\text { accordance with the operation standards of the Korea Nursing } \\
\text { Association and be responsible for judging and acting in connection with } \\
\text { nursing. }\end{array}$ & $3.48(0.95)$ & $4.25(0.53)$ & $0.77(1.21)$ & $4.424(<.001)$ \\
\hline $\begin{array}{l}\text { Education and research: Nurses should participate in education and } \\
\text { training for improvement of nursing ability and evidence-based practice, } \\
\text { and contribute to the development and research of nursing standards. }\end{array}$ & $3.44(1.05)$ & $4.13(0.67)$ & $0.69(1.27)$ & $3.738(.001)$ \\
\hline $\begin{array}{l}\text { Professional activity: Nurses should participate in the improvement and } \\
\text { development of nursing policies and related systems through } \\
\text { professional activities. }\end{array}$ & $3.35(1.08)$ & $4.33(0.67)$ & $0.98(1.44)$ & $4.723(<.001)$ \\
\hline $\begin{array}{l}\text { Promotion of justice and trust: Nurses should maintain equality and } \\
\text { fairness in the distribution of medical resources and nursing activities, } \\
\text { and participate in the promotion of common good and trust in the } \\
\text { society. }\end{array}$ & $3.63(0.98)$ & $4.41(0.58)$ & $0.79(1.32)$ & $4.155(<.001)$ \\
\hline $\begin{array}{l}\text { Provision of safe nursing care: Nurses should take human dignity, } \\
\text { values, and personal safety as a priority throughout the whole process of } \\
\text { nursing and take actions to minimize risks. }\end{array}$ & $3.90(0.86)$ & $4.54(0.50)$ & $0.65(1.08)$ & $4.137(<.001)$ \\
\hline $\begin{array}{l}\text { Maintenance of health and dignity: Nurses should protect their own } \\
\text { health and maintain their pride and decency as professionals. }\end{array}$ & $3.58(1.00)$ & $4.33(0.63)$ & $0.75(1.18)$ & $4.418(<.001)$ \\
\hline Nurses and cooperators & $3.72(0.79)$ & $4.34(0.45)$ & $0.63(0.87)$ & $4.969(<.001)$ \\
\hline $\begin{array}{l}\text { Respect of relational ethics: Nurses should perform ethical obligations } \\
\text { for nursing clients and society when working with professionals and } \\
\text { employees of industries related to medicine. }\end{array}$ & $3.63(1.08)$ & $4.25(0.53)$ & $0.63(1.10)$ & $3.923(<.001)$ \\
\hline $\begin{array}{l}\text { Protection of patients: Nurses should take adequate actions in situations } \\
\text { where the health and safety of nursing clients are threatened. }\end{array}$ & $4.08(0.74)$ & $4.62(0.49)$ & $0.54(0.90)$ & $4.178(<.001)$ \\
\hline $\begin{array}{l}\text { Protection of life, science and technology, and dignity of patients: } \\
\text { Nurses should protect the dignity of human life and nursing clients from } \\
\text { biotechnology-based procedures that are not safe. }\end{array}$ & $3.46(1.00)$ & $4.17(0.63)$ & $0.71(1.13)$ & $4.346(<.001)$ \\
\hline
\end{tabular}


Worldwide, education on nursing ethics is gaining importance owing to the emphasis of nursing science education on the understanding of legal and ethical standards as a key capability of nurses, and acknowledgement of the significance of awareness regarding concerned responsibilities. ${ }^{[12,23]}$ Therefore, it is necessary to develop guidelines and educational methods for ethics education in a variety of contexts.

This study is limited in that the influence of ethics education on the awareness about the code of ethics was measured in a single group. The absence of a control group made it difficult to determine the direct influence of ethics education on the nursing students' awareness. In addition, the participants were limited to students from one university, which makes it difficult to generalize the results to all university students majoring in nursing science in Korea. Further, as only nursing students with no clinical experience were targeted, it may be difficult to generalize these findings to nursing students with clinical experience.

\section{Conclusion}

Ethics education is indispensable for building a desirable ethical value system and cultivating students' talents that will enable them to practice ethical behaviors by improving their ethical judgment and sensitivity. Particularly, awareness regarding and practice of the code of ethics is crucial for ensuring morality in the occupational behaviors expected from medical professionals.

In this study, ethics education was found to raise awareness regarding the code of ethics. In future studies, it may be necessary to develop grade-specific ethics education programs suited to the level of ethics education of the students, as well as to provide continuous ethics education programs in all grades of nursing education. Additionally, these results reflect the need for ongoing efforts to develop innovative content, structure, and instructional methods for undergraduate nursing ethics education programs. Moreover, further research needs to be conducted to identify ways to improve awareness regarding the code of ethics among both nursing students and practicing nurses, and to help develop their ability to apply this awareness in their clinical practice.

\section{CONFLICTS OF INTEREST DisClosure}

The author declares that there is no conflict of interest.

\section{REFERENCES}

[1] Kangasniemi M, Pakkanen P, Korhonen A. Professional ethics in nursing: an integrative review. Journal of Advanced Nursing. 2015; 71(8): 1744-1757. https://doi.org/10.1111/jan.12619

[2] Callister LC, Luthy KE, Thompson P, et al. Ethical reasoning in baccalaureate nursing students. Nursing Ethics. 2009; 16(4): 499-510. https://doi.org/10.1177/0969733009104612

[3] Choe K, Song E, Kang Y. Recognizing bioethical issues and ethical qualification in nursing students and faculty in South Korea. Nursing Ethics. 2013; 20(2): 213-225. https ://doi .org/10.1177/0969 733012472734

[4] Monrouxe LV, Rees CE, Dennis I, et al. Professionalism dilemmas, moral distress and the healthcare student: insights from two online UK-wide questionnaire studies. BMJ Open. 2015; 5(5): e007518. https://doi.org/10.1136/bmjopen-2014-007518

[5] Mohajjel-Aghdam A, Hassankhani H, Zamanzadeh V, et al. Knowledge and performance about nursing ethic codes from nurses' and patients' perspective in Tabriz teaching hospitals, Iran. Journal of Caring Sciences. 2013; 2(3): 219-227.

[6] Han SS, Park HA, Ahn SH, et al. Korean nursing students' experience of ethical problems and use of ethical decision-making models. Journal of Korean Academy of Nursing. 2001; 31(5): 846-857. https://doi.org/10.1191/0969733003ne653oa

[7] Vanlaere L, Gastmans C. Ethics in nursing education: learning to reflect on care practices. Nursing Ethics. 2007; 14(6): 758-766. https : //doi.org/10.1177/0969733007082116

[8] Stolper M, Molewijk B, Widdershoven G. Bioethics education in clinical settings: theory and practice of the dilemma method of moral case deliberation. BMC Medical Ethics. 2016; 17(1): 45. https ://doi.org/10.1186/s12910-016-0125-1
[9] Han SS, Ahn SH, Kim HG, et al. The process of the third amendment of the Korean nurses' code of ethics. Korea Nursing. 2006; 44(3): 63-81.

[10] Epstein B, Turner M. The nursing code of ethics: its value, its history Online Journal of Issues in Nursing. 2016; 20(2): 4.

[11] Korean Nurses Association. Korea nurse ethics. 2013. Available from: http://www.koreanurse.or.kr/board/board_r ead.php?board_id=notice\&no $=66$

[12] Korean Accreditation Board of Nursing Education. Nursing education accreditation. 2012. Available from: http://kabon.or.kr/eng/

[13] Yeom HA, Ahn SH, Kim SJ. Effects of ethics education on moral sensitivity of nursing students. Nursing Ethics. 2016 Jan 24 PMid:26811393 https ://doi.org/10.1177/09697330156220 60

[14] Numminen OH, van der Arend A, Leino-Kilpi H. Nurse educators' and nursing students' perspectives on teaching codes of ethics. Nursing Ethics. 2009; 16(1): 69-82. https://doi.org/10.1177/09 69733008097991

[15] Tadd W, Clarke A, Lloyd L, et al. The value of nurses' codes: European nurses' views. Nursing Ethics. 2006; 13(4): 376-393. https://doi.org/10.1191/0969733006ne891oa

[16] Choe K, Park S, Yoo SY. Effects of constructivist teaching methods on bioethics education for nursing students: a quasi-experimental study. Nurse Education Today. 2014; 34(5): 848-853. https : //do i.org/10.1016/j.nedt.2013.09.012

[17] Lin CF, Lu MS, Chung CC, et al. A comparison of problem-based learning and conventional teaching in nursing ethics education. Nursing Ethics. 2010; 17(3): 373-382. https : //doi .org/10.1177/09 69733009355380 
[18] Korean Academy of Nursing Administration. The learning objectives of nursing management, the part of nursing philosophy and ethics, professionalism. 2012. Available from: http://www . kanad.or.kr/index.php?page=view\&pg=1\&idx $=20 \& \mathrm{hCode}=$ BOARD\&bo_idx=10\&sf $\mathrm{l}=$ \&st $\mathrm{x}=$

[19] Kim YS, Kang SW, Ahn JA. Moral sensitivity on the application of code of ethics. Nursing Ethics. 2013; 20(4): 470-478. https: //doi.org/10.1177/0969733012455563

[20] Aleksandrova-Yankulovska S. An innovative approach to teaching bioethics in management of healthcare. Nursing Ethics. 2016; 23(2): 167-175. https://doi.org/10.1177/0969733014558967
[21] Schwartz B. An innovative approach to teaching ethics and professionalism. Journal of Canadian Dental Association. 2009; 75(5): 338-340. PMid:19531330

[22] Vanlaere L, Gastmans C. Ethics in nursing education: learning to reflect on care practices. Nursing Ethics. 2007; 14(6): 758-766. https://doi.org/10.1177/0969733007082116

[23] Kim HS. Outcomes-based curriculum development and student evaluation in nursing education. Journal of Korean Academy of Nursing. 2012; 42(7): 917-927. https://doi.org/10.4040/jkan. 2012. 42.7 .917 